\title{
Urban Hybridization*
}

\author{
Jingwen Shan \\ Department of Urban, Architectural and Interior Design \\ Politecnico di Milano \\ Milano, Italy
}

\begin{abstract}
Urban hybridization, as the contrary of zoning, has a great advantage in planning and designing spaces. This age of interlace cultivate a rich soil for the development of the urban hybridization. The ideology of urban hybridization can be widely applied in urban planning, design of public spaces, architecture design and interior design. There are four forms of urban hybridizations involving hybridization of nature and artificial, multi-functions, fragments of buildings, public and private, built and non-built and so on that will be discussed in the following paper respectively, with some case illustrations. Subsequently it comes to many open thinking about the strategies and methods that can be explored in the future.
\end{abstract}

Keywords-hybridization; nature; multi-functions; modularity; public; private; built; non-built

\section{INTRODUCTION}

It is witnessed by all that the process of globalization in the past few decades. Fast and convenient transportation enables mass of goods trading and migration. World becomes smaller. Public media informs the people of this age influencing daily events that happen in each corner of the world. With the everincreasing knowledge of this earth and its land, people are open-minded to personally explore new lands on the small planet. Large amount of tourists, immigrants appeared, as well as refugees. In international metropolitans, different nationalities, various cultures conflict and diffuse.

Mix races appeared where interracial relationship takes place. In 1993, TIME Magazine published an issue multiculturalism in America, the cover of which featured an ethnically ambiguous woman over the caption "The New Face of America: How Immigrants Are Shaping the World's First Multicultural Society". The model was computer generated by merging men and women from various racial and ethnic backgrounds [1]. It was just the beginning. A 2010 study found that between white, black and mixed-race faces millennials considered mixed-race to be the most attractive.

It is inspiring to see this result from the perspective of urban development. The hybridizing process will eventually happen to cities, environment, architecture and landscape. Multi-cultural and multi-functional spaces and design are something inevitable that will emerge over time.

\section{HYBRIDIZATION AS A CHARACTERISTIC OF CONTEMPARARY ERA}

Hybridization is a process that mix different species or

\footnotetext{
*This paper work is sponsered by China Scholarship Council.
}

varieties of animals or plants and thus to produce hybrids. Hybrid is the offspring of two animals or plants of different breeds, varieties, species or genera etc. as produced through human manipulation for specific genetic characteristics.

Urban hybridization can be a mode of action of architectural and urban design. It is a possible process that is opposed to the urban space structured by zoning, for monofunctional areas and for replication of stereotyped typologies of settlement. It is also a special condition in which occurs in certain places and under certain conditions of widespread contemporary urban space. The urban hybridization process can be connected to the urban morphogenesis theory developed by Professor Sergio Crotti. The urban hybridization is related to the presence or the development of hybrid forms of settlement and hybrid building typologies. It is also a form of architectural and urban design to build a composition of architectural and urban space through the intersection of different kinds of spaces, according to a conception of genetic and non-deductive logic of the project.

\section{CONVERSATION WITH NATURE}

The first form of urban hybridization is between culture and nature, or between architecture and nature. Antonio Saggio says that the idea of hybridization in the treatment of land and vegetation together with space and architecture is developed in the sixteenth century in Rome.

The hybrid of artificial space and natural space is superior of the simple artificial one. In any age of society, people never lose their nature connectedness, in the sense that individuals include nature as part of their identity. Especially in the over urbanization today, people suffer when they withdraw from nature. The mix of nature can bring human sense alive. Moreover, each area has its own unique terrain and vegetation. Consequently, involving natural landscape to architecture project, the architecture works exudes a heavy local feature. Also, nature has four seasons a year, thus the landscape architecture differs throughout various seasons, allowing users to have a richer experience, while in turn reflecting the present season from the building. The California State Route for instance, exposing Tropical desert climate mixed with Mediterranean climate and partly Alpine climate surface and its wild landscape, lays travellers an impression beyond description.

The hybrid is also more meaningful than the pure natural one, since it is environment with purpose created by human. The ambience serves better the users of the space. An ideal 
application can be the interaction between architecture and nature, not monotonous piling up. Apollo Naxos gateway set an artificial frame for the sun, giving new meaning for the sun and the place. The view changes every minute and second with the trajectory of the sun and its light and shadow.

The Pritzker Prize winners in 2017, Spanish architects Rafael Aranda, Carme Pigem and Ramon Vilalta are famous for working with environs. The organic integration of nature and architecture creates a site that dedicated to its specific location and times. The idea of hybridization between nature and culture, including natural space and artificial space for realization of a hybrid architecture is characteristic of the contemporary.

\section{MIXITE}

The second form of urban hybridization is the coexistence and intermingling of different urban functions in a single area. In urban design this condition is defined firstly in a French word "Mixite", co-presence of new and different activities especially designed for the construction of parts of cities with a new vitality.

Space as a form of container, has the potentiality of carrying different functions. The famous Campo Piaza in Siena is a classic one, regarded as one of Europe's greatest medieval squares. The piazza is alive all the year long with its nice slope that nice to walk, stay and involve in various social activities, and perfect for people to lay down relaxing and observing the whole public space. Especially when it comes the Siena traditional annual horse race season, the square can embrace thousands of audience and provide amazing view of the game.

Cities keep expanding. Small cities turn into large cities, large cities become metropolis, metropolis fosters a series of satellite cities. Residents need to travel from place to place among different functional zones in their daily life. As a result, more energy and resources are wasted. For instance, large shopping malls in suburb, huge parking lots, etc. Commuting takes more time than ever. Urban morphology involves what is the form of the city, a regressive process of enclosure and separation of mono-functional protected areas.

Anther fact of Zoning is that it limits the usage value. The physical isolation of each function resulted in single function is only used in a certain time of a day or a specific period of a year. Residential zones become sleeping area where people only go there to sleep during night. Los angels city center, for instance, is known as empty city or "ghost downtown" in evening, for the lack of other lively activities functions and facilities in the center area. People leave for home or some other functional zones after finishing work in their offices and those big office buildings stand empty and without lights in the downtown zone, with just few homeless and refuges sleeping on the street, the safety issues as a consequence become worse than ever.

Compared with zoning cities, compacted ones are much more reasonable considering sustainability as well as social security.

\section{FRAGMENTS OF A BUILDING}

The third form of urban hybridization is the interference between pieces taken from different building and urban types reassembled in a new hybrid form.

On the on hand, the combination of multiple functional pieces enriches the life inside a building. This process is not new. A successful case is hotels in Las Vegas, a compacted building in which people can access to any type of recreational spaces and facilities that they are looking for. The original materials include a central strip, a single building with garden. The mechanism of the hybrid construction begins by propagating and overlapping multiple levels of individual hotels, followed by the transformation of a city street with casinos, show rooms, shops, restaurants, gyms, swimming pools, SPA, etc. in either inserted in building and finally superimposing a garden, as a collective architectural garden on top of the building.

Moreover, there is a recent popular concept for elderly housing that mix kindergarten and some other functional facilities into the ground floor of elderly housing building design. In this way, mutual activities can happen between children and elderly people so that the young can be nicely taken care of while the old have the accompany. Hybridizing several specific kind of functional space could benefit each side of users, which demonstrates the Dutch architect F. van Klingeren's formula "one plus one is three - at least". Anther fact that can be seen from this concept is the importance of the order of mixing. Only the mixed pieces work good with each other can result in a nice user experience, otherwise one plus one might smaller than two. In terms of which functional pieces should be hybridized and which ones should not depends on the judgment of architects.

On the other hand, this method can also be supported by the building metabolic theory. Architectures that are built with modular pieces can be easily transferred according to different needs of its users throughout time. The unwanted parts will be substituted with new desired ones. Especially the in-filled architectural structure made a great framework for the modularity. The Pompidou Art Center by Richard Rogers and Renzo Piano for instance is a great example. The exposed metal framework could be flexible catering to various functional demands.

\section{LIFE BETWEEN BUILDINGS}

The fourth form of urban hybridization is connected to a new and innovative presence and intermingling of public spaces, built and not built, public and private, functions and spaces.

Built and non-built space sometimes can be converted reversible. For example, Italian square as a crucial public space for their citizen, if the top of the surrounding house was removed to cover the square, then the internal space and external space will be reversed. The previous non-built space becomes the built space. Here a conclusion can be drawn that the crucial role a roof plays in terms of a built or non-built space. With or without a roof defines space. Space covered with roof represents the built space, which space not covered with roof is the non-built one. However, on some 
circumstances, roof extends from the built one far away to the non-built one, and forms a semi-built space. For example, in Usonian Houses that conceived by Frank Lloyd Wright, commonly featured flat roofs reach out from the core of the building to its surrounding wide nature, creating a cozy buffer zone that links interior with exterior, artificial with nature, building with environs. That buffer zone is an ideal case of the hybridization of built and non-built space.

Anther significant element, walls. Ancient European architectures all share the common thick and irregular bearing facades until the frontispiece of Essai sur I'Architecture by MarcAntoine Laugier from 1755, showing and allegorical image of the Vitruvian primitive hut, releases architectures from the establishment of walls. A covered shelter can be an ideal form of architecture. Buildings without walls engage much more surrounding environment and nature, which also leads to better circulation in hot weather and more evenly penetration of sunlight. Indoor and outdoor have a direct physical connection that enables wider social activities.

In the Nolli map, streets and squares are not the only ones to be left white but also the interiors of churches and other major public buildings. In the way, what the figure-ground reveals is the relationship between public and private space. Figure-ground relationship shows the hierarchical distribution of foreground and background spaces. Degrees of privacy define various places. Urban morphology destruction of the relationship between settlement and land: private paradise and public hell. However, there is no black and white case. The middle ground and transition between private and very public territory make semiprivate and semipublic spaces. The semiprivate and semipublic spaces are the hybrids of private and public.

In old Australian towns, dwelling units commonly have a front yard next to streets as well as a private backyard, which provide people the choice to choose between semi-private and completely private. A study shows that people mostly prefer the former one rather than the later. The popularity of semiprivate yard reveals the strength of hybridization of public and private. The hybridization space is born with more dynamic passion and exciting potential socialization involvement.

Anther brilliant experiment that could be used in certain cases, two flats share balcony while having independent living rooms, bedrooms, kitchens and bathrooms. The shared balcony is a semiprivate space that can be accessed by owners of these two flats but not other people. It can be designed for the lonely group of society, as a potential communication space that could cultivate interaction but also keep the necessary privacy.

Hybridization of built and non-built space is playing with mass and void, in order to include mass in void and also void in mass. The built and the non-built share the same importance. Peter Eisenman in his Cannaregio project in Venice, in the context of the Derridean notion of absence and presence, created a grid with the physical traces left by the previous building, and then he made holes. "But also, is the ground the holes or is the ground the stuff ground the holes?" Eisenman asked [2]. The void container of grid combined with few mass building. The space articulates certain amount of energy, concentration, and participation.

\section{CONCLUSION}

We are living in an era of interlace. Urban planners and architects are facing newly emerged problems and challenges such as pollution, climate change, population exploration, immigrations, refugees, etc. It is indeed necessary to think out of box and combine multiple disciplines and fields in order to find nice solutions. Urban hybridization process is inevitable. It brings new life to our society and generation. The ideology of urban hybridization can be applied in multiple fields of subjects and ways.

Possible strategies and methods of intervention of urban or large-scale architectural design are entrusted to a vision that goes beyond the separate logics of action, to consider for specific areas all possible urban interactions. In the early research, vacuums have been discovered where fusion take places: the intertwining program and infrastructure in conditions of high compression. As fusion creates new programs and performs best with flexible and variable programming, the infrabodies are organized neutrally to allow absorption of a wide variety of program [3]. Concerning the relationship between land, urban landscape and infrastructure, there are many possibilities for intervention: hybridization of the sprawled (diffused) areas, typologies and textures of urban edges, "highway-scape", typologies of public urban spaces, "ground-scape", in-between design strategies, urban porosity, etc. There are many evolutionary realms to be explored.

\section{ACKNOWLEDGMENT}

First, I am very appreciated that China Scholarship Council sponsored my PHD research in Politecnico di Milano when this paper came out. Secondly, I would like to thank Prof. Fabrizio Zanni, director of Urban Hybridization International Research Group (UHRG), who first introduced the urban hybridization idea to me logically and systematically. The last but no least, thank Prof. Luca Basso Peressut, my PHD coordinator, head of Dastu department of Politecnico di Milano for his patient guidance from the first beginning of my PHD career. Architecture Form, Space and Order by Frank Ching has always being the guideline throughout my architectural career. Cities for a small planet by Richard Rogers provokes deep insight of what a nice and sustainable city could be. Life between Buildings by Jan Gehi opens the gate of outstanding design of public spaces for me.

\section{REFERENCES}

[1] www.racismreview.com.

[2] Ansari, Iman. Architectural Review, 2013

[3] www.monolad.nl. 